\title{
Global environmental justice and biodiversity conservation
}

\author{
ADRIAN MARTIN*, SHAWN MCGUIRE* AND SIAN SULLIVAN† \\ *School of International Development, University of East Anglia, \\ Norwich Research Park, Norwich NR4 7TJ \\ tDepartment of Geography, Environment and Development Studies, Birkbeck College, London \\ E-mail: adrian.martin@uea.ac.uk
}

This paper was accepted for publication in January 2013

\begin{abstract}
This paper explores the potential for an environmental justice framing to shed new light on conservation controversies. We argue that, in order to make such progress, environmental justice analysis will need to provide a 'difference-friendly' conception of justice and that this will necessarily involve moving beyond dominant liberal conceptions of distributional fairness. We are largely welcoming of global deployments of distributive justice principles. However, we also explore the dangers of focusing on distribution alone, questioning the assumption of positive relationships between benefit sharing and more culturally defined dimensions of justice such as recognition. The limits of access and benefit sharing for delivering justice writ large is that it can disenfranchise people who are less well equipped or less willing to navigate its prevailing system of knowledge. We argue that, especially in the context of resource poverty, efforts to improve distribution can require potential beneficiaries to assimilate to dominant discourses of society and nature. Such conditionality can contract the opportunities for local and autonomous constructions of 'different' ways of knowing nature, and in doing so may also contract possibilities for flourishing biodiversities.
\end{abstract}

KEY WORDS: environmental justice, distributive justice, procedural justice, recognition, biodiversity conservation, payments for ecosystem services

History will recall that it was here in Nagoya that a new era of living in harmony was born and new global alliance to protect life on earth was established ... Nagoya will be remembered as the city where the biodiversity accord was born.

Ahmed Djoghlaf, Executive Secretary of the UN Convention in Biodiversity (CBD), quoted in Secretariat of the CBD $(2010,1)$

The conference [CBD COP 10, Nagoya] was marked by a significant divide between developing countries and industrialized countries over market-based and other pro-business approaches to biodiversity. While the EU and other Northern countries pushed for market-based mechanisms, including as a financial resource for biodiversity conservation, many Southern countries pointed at the serious environmental and social risks of these mechanisms ...

Global Forest Coalition (2010)

$\mathrm{T}$ hese different reflections on the same conference illustrate that justice is a contested notion in biodiversity conservation, as it is elsewhere. Notions of justice - from access rights, to deliberative processes shaping decisionmaking, to the sharing of economic benefits - permeate debates regarding environmental issues and are infused with tensions arising from centuries of colonial exploitation, global economic inequalities, and the challenges of aligning different ways of knowing and valuing nature.

This paper explores the potential for an environmental justice (EJ) framing to shed new light on such old controversies. Our main argument is that, in order to make such progress, EJ will need to move beyond a focus on the distributive dimension of justice to engage with the dimension of 'recognition'. We will argue that 'justice-as-recognition' complements other dimensions of environmental justice and provides the most promising conceptual approach to resolving tensions between social and ecological values. We agree with Nancy Fraser (2001 2009) and David Schlosberg (2004 2007) that justice in this age of globalisation requires us more than ever to enquire into the structural causes of maldistribution, but that a focus on distribution alone may not address underlying mechanisms of injustice, and may even reinforce them. To illustrate, we cite cases of conservation in developing countries where efforts to improve distribution can 
require potential beneficiaries to assimilate to dominant ways of knowing and living with nature, or dominant approaches to consensus and decisionmaking. Such conditionality can contract the opportunities for local and autonomous constructions of 'different' socionatures, perpetuating a form of injustice based on lack of recognition. Where efforts to promote justice are not sensitive to recognising cultural difference, they may even contribute to eroding one of the world's most important 'diversity' sources that some argue is inextricably linked with the flourishing of biological diversity (Maffi 2001).

We begin the paper by defining the terms used to describe different dimensions of environmental justice. We highlight the dominant western liberal tradition of distributive justice, how this dominated early, state-based applications of environmental justice analysis, and how the globalisation of environmental issues poses challenges to such a framing. We then employ these environmental justice concepts to explain how inequalities have historically been produced through biodiversity conservation. In order to emphasise the more discursive roots of the production of injustices, we introduce the notion of dominant 'ways of knowing' (cf. Belenky et al. 1986) and consider how these may pose an obstacle to the uptake of insights about recognition from environmental justice analysis. As an illustration, we discuss how the term 'biodiversity' can be employed in ways that perpetuate dualist thinking about society and nature, potentially excluding recognition of alternative cosmologies. We then proceed to explore the apparent limitations of confining justice thinking to matters of distribution and not engaging with the more overtly political agenda of recognition. To do this, we briefly look at global efforts to achieve more just distribution of conservation costs and benefits through access and benefit sharing (ABS) under CBD architecture and through payments for ecosystem services (PES). In light of these limitations we consider why the field of biodiversity conservation has found it difficult to take on board justice-as-recognition, despite the insights provided by environmental justice analysis. We argue that, in effect, such insights have been discursively excluded from biodiversity practice due to the prevailing dualism in modern environmentalism: the separation of nature and society. The problem of dualism and the problem of recognition are strongly connected and we proceed to an exploratory conclusion that embracing justice-as-recognition can help to resolve tensions between social and ecological priorities. In the final part of the paper we explore a little further the connection between the society-nature dualism and the separation of justice-as-distribution from justice-as-recognition. In doing so we make an admittedly preliminary case that challenging these twin dichotomies provides us with a way of approaching the problem of reconciling social justice and environmental sustainability (cf. Dobson 2007).

\section{Beyond distributive justice}

According to Vincent $(1998,137)$ 'the only area of justice theory that is clearly relevant to the environment is distributive justice'. In contrast, we follow Schlosberg (2007) and propose that an understanding of biodiversity conflicts will best be served by a multidimensional conception of justice that also emphasises procedure and recognition, especially where values of social justice and environmental sustainability confront each other. Distributive justice is concerned with benefit and burden sharing: who gets what, who has to live with what (Walker 2012), and what moral principles can be employed to make normative claims about just and unjust distributions. Biodiversity conservation raises a range of intra- and intergenerational distribution concerns which highlight the importance of distributive justice principles (e.g. Jamieson 1994). Among the most persistent is the concern that the poor pay a disproportionate cost for conservation, while the rich secure most of the benefits (Chan and Satterfield 2007). Issues of distribution are intensified by the unequal spatial distribution of biodiversity (Gaston 2000), including areas classified as 'hotspots' (e.g. Brooks et al. 2002), as well as by the uneven and changing distributions of people in proximity to such locations (e.g. Wittemyer et al. 2008). They are also intensified by the irreversibility of species loss, an important quality of biodiversity that serves to harden intergenerational concerns and adds heat to conflicts between local proprietary demands and claims for the national, global and future public good. Conflict between local access and territory on the one hand, and putative common heritage benefits on the other, reveals a chasm between consequentialist (utilitarian concerns about distributional outcomes, in which ends may justify means) and deontological (ex ante concerns with rights, rather than outcomes) thinking about justice. Determining just distribution may be based on an attempt to determine what individuals or groups deserve to receive, or gaining agreement regarding a fair procedure for allocation (Vincent 1998). Thus procedural justice is closely connected to distributional justice. It is about how decisions are made, who is included in these processes and, again, about the principles that we use to make normative claims about just or unjust procedures. Matters of procedure commonly appear in conservation policy documents as commitments to local community participation and to securing their informed consent. Procedure might be based on rational contractarian principles (John Rawls being a towering example of this thinking; e.g. Rawls 1999 [1971]) or based on agreed empirical needs such as freedom from violence, hunger and easily curable diseases (Schroeder and Pogge 2009).

We believe that recognition offers a distinct and important additional conception of environmental justice (cf. Fraser 1997), while noting, with Lois 
McNay (2008), the significant structural constraints and inequities that prevent recognition possibilities from emerging. The particular relevance of justice-asrecognition to the field of biodiversity conservation stems from the fact that there are often considerable cultural differences between negotiating parties, including culture-nature cosmologies and views of what constitutes just distribution or procedure (de Jonge 2011; Whiteman 2009). Recognition is about seeking equality between different ways of knowing the world (de Jonge 2011), or put another way, about being reflexive regarding whose culture is privileged and respected (Walker 2012). An emphasis on distributional or procedural justice by no means guarantees such respect. One outcome is that schemes focusing on distributional aspects, such as biodiversity ABS schemes, may be perceived by local communities as culturally dominating (Whiteman 2009; de Jonge 2011; Vermeylen and Walker 2011). In these circumstances, as Harvey $(1996,398)$ notes, 'conflict is not between just and unjust solutions but between different conceptions of justice'.

In the tradition of twentieth century western liberalism, distributive justice has largely developed as a state-based function, enshrined in national sovereignty, citizenship and the welfare state. Economic and political dimensions of globalisation challenge the adequacy of this basis for justice (Fraser 2009). For example, the UN Convention on Biological Diversity (ratified in 1993) is oriented towards state-based distribution systems based on sovereignty, and because of this, is often challenged by causes and consequences of biodiversity erosion that lie beyond states. Indigenous peoples' struggles over biodiversity may also have both 'roots and wings' (Castree 2004, 136), being place based at the same time as invoking and organising around global referents, such as the UN Declaration on the Rights of Indigenous Peoples. While a state-based conception of justice has become inadequate, so too has one based on distribution of costs and benefits alone (Schlosberg 2004 2007). This observation becomes increasingly evident as one looks beyond state-based analysis to consider wider causes that underpin or connect particular cases of distributional injustices. Environmental justice is also about politics and the power to speak of and manifest values that are not only economic. This takes us into the realm of identity-based arguments for recognition and, in particular, the lack of status and respect for marginalised groups.

The US environmental justice movement initially focused mainly on issues of distribution of toxic waste within the Unites States (Bullard 1990) but was not confined to identifying inequality of distribution. The production of injustices was claimed to be rooted in the institutional racism and classism that denied just decisionmaking about dump site locations. Likewise a globalised environmental justice analysis applied to biodiversity conservation needs to address the struc- tural causes that suppress some groups and allow others to dominate. This analysis of 'recognition' must consider how status hierarchies bias distribution and procedure for different identity groups (related, for example, to gender or ethnicity). We propose here that the domination of certain 'ways of knowing' nature contributes to the persistence of such status hierarchies. This includes the dominant environmental economics perspectives that underscore discourses of mutual benefit arising from pricing and commodifying nature (McAfee 1999; Spash 2010). This point becomes clearer if we define justice-as-recognition as aiming for a state of affairs in which all people have the right to equal respect, and equal opportunity to participate, benefit and avoid harms, without this being conditional upon assimilation into dominant cultural norms (Fraser 2001; Bohman 2007). Notwithstanding the political difficulties of generating contexts for 'fair hearing', adopting the lens of recognition might provide an opportunity to reconcile social justice with environmental sustainability, especially if it is accepted that cultural diversity may be beneficial to, or at least compatible with, biological diversity. This is really the essence of our argument - that if we agree on the premise that biological and cultural diversity are compatible, then a 'difference-friendly' cosmopolitan cultural politics might correspond with a politics of sustainability. We proceed by considering how this lesson emerges from a history of biodiversity conservation, as seen through a multidimensional environmental justice analysis, while also emphasising how this lesson has proven hard to learn in conservation practice.

\section{Lessons from history}

The setting aside of land areas for the conservation of particular species and habitats has long been associated with both restricted access to these 'resources' by élites, and the displacement or criminalisation of access by peoples less able to command economic and political dominance. The historical acquisition and consolidation of large landed estates and conserved hunting grounds in the UK, for example, frequently required the eviction of whole villages and the criminalisation of former practices for resource use on land thereby acquired. Thus Marx notes the destruction of 36 villages in 1079 by William the Conqueror of Normandy, so as to create a royal hunting ground of the New Forest in south England (Marx 1974 [1887], 685), a practice that was extended as deer parks were created in expanding estates throughout the country in Renaissance England (Nicolson 2009). The early 1700s saw the systemic criminalisation of resource use and access on remaining forest and common lands through the infamous 'Black Acts', which overrode 'customary procedure and the defences of the subject' to create 'at a blow some fifty new capital offences' linked with 
the hunting and accessing of other items from lands including forests, commons, heaths and parks (Thompson 1977, 21-2). This clearance model was exported to the New World landscapes of North America through the later creation of the first National Parks of Yellowstone and Yosemite, a process redolent with militarised management regimes and the evictions of indigenous peoples who had shaped these new 'wilderness' landscapes (for histories of biodiversity conservation through the setting aside of land in conserved areas, see, for example, Adams 2004; Brockington et al. 2008). The subsequent transfer of this model to Old World situations, particularly in Africa, has naturalised a problematic ideal of wilderness landscapes as empty of people, when this in fact is manufactured through the removal of indigenous and local human use and habitation (Brockington and Igoe 2006; Dowie 2009).

Viewed through a contemporary environmental justice analysis, such displacements engender clear justice transgressions, including human rights abuses and the ignoring of just about all procedural, distributive and recognition justice practices. Their extension into the current moment is indicated by the recent mobilisation for a Conservation Initiative on Human Rights (CIHR) through which such injustices might be identified and addressed. Amidst global calls for inclusive and 'sustainable development' - including through the 1972 Stockholm Conference on the Human Environment, the World Conservation Strategy (1980), the 1992 Earth Summit (which saw the establishment of the UN Convention on Biological Diversity) and the UN Millennium Development Goals (2000) - conservation practice in recent decades has responded with a surge of energy around finding ways both to redress past injustices and to create new policies and practices that are more inclusive. Through the work and funding of organisations such as the IUCN, USAID, the major international Environmental NGOs, and national Ministries and implementing NGOs and agencies, these have emerged as combined conservation and development initiatives, including Integrated Conservation and Development Projects (ICDPs) and Community-Based Natural Resources Management (CBNRM). These initiatives have tended to focus on both distributive and procedural issues, emphasising to varying extents, and with varying outcomes, both the distribution of benefits, and participation in decisionmaking processes and consultations. The policy documents of conservation NGOs and UN CBD also typically include some reference to recognising indigenous culture and knowledge (e.g. Greiber et al. 2009; WWF 2008; WCS 2009; BirdLife International 2011), but this is much less evident in field practice, where the emphasis is on implementing participatory consultations and benefit-sharing schemes.

Partly as a result of the rather notional attention to what we are calling recognition, these efforts at pro- moting justice have come under criticism for reducing benefits to monetary payments, and decisionmaking processes to externally led structures that are neither initiated by, nor mesh well with, local values and realities. This is compounded by a current 'Green Economy' emphasis (e.g. UNEP 2011; World Bank Group 2012) that privileges market-based solutions to conservation problems (including PES, a REDD+ mechanism (reducing emissions from deforestation and forest degradation in developing countries) and ABS agreements), and limits possibilities for redress and compensation to monetary measures within the dictates of a neoliberal discourse that tends to foreclose alternative values. Concerned social movements of peoples living in remaining biodiverse landscapes instead are embracing 'rights-based approaches' that prioritise 'rights to lands, territories and resources; recognition of traditional knowledge and traditional practices; and respect for indigenous peoples' own governance structure and equitable benefit-sharing' (Workshop Report 2012, 3). In other words, arguably it is the right to be recognised on one's own terms that is animating current calls for rights and appropriate justice in relation to biodiversity and other environmental parameters.

\section{Ways of knowing (or 'ways of not recognising')}

Since its coinage in the 1980s (Wilson 1988), the term 'biodiversity' has become common parlance for conservation scientists. Broadly describing the variation of life at all scales of biological organisation - from molecules to ecosystems - biodiversity is commonly seen as essential for maintaining healthy and resilient natural systems, and for continued evolution. The rapid rate of biodiversity loss, particularly in the tropics, is one of the pressing environmental and social concerns of our time, and human activity is a major cause of this (Schipper et al. 2008; Zalasiewicz et al. 2010; WWF, 2010). The preservation of remaining biological diversity is generally seen as critical, and animates a range of in situ and ex situ global policy approaches, including the establishment of enclosed land- and seascapes whose primary form of use is conservation, and the creation of zoos, herbaria and seed banks (cf. Pistorius, 1997; Carroll et al. 2008; Briggs et al. 2009).

Though referring to concrete biophysical phenomena, biodiversity is also 'a discursive invention of recent origin' around which a complex network of actors now revolves, 'composed of sites with diverging biocultural perspectives and political stakes' (Escobar 1998, 53). It can appear to delineate biological realms as distinct from other environmental phenomena, as well as from human activity. By supporting such separation, 'biodiversity' is a conceptual construct for understanding life that in fact may engender profoundly 'unecological' thinking, by disassembling life's entities both from each other and 
from the complex environmental contexts necessary for sustenance at all scales (following Deleuze and Guattari 1987 [1980]; Latour 2004 2005; De Landa 2006). Similarly, we should at least be sensitive to the cognitive implications of selecting an 'ecosystem services' framework, which (like other choices of framing before it) contracts our ways of knowing biodiversity and nature in general, with the associated cost of crowding out much of the rich variety of ecological thinking (Norgaard 2010).

While a modern science of conservation biology may consider biodiversity conservation implicitly to require at least some separation of 'wild nature' from people (e.g. Terborgh 1999), this distinguishing of natural history from human dwelling is itself an understanding and orientation associated with the constructions of human and non-human nature guiding European Enlightenment ideals. It is a particular cognitive and cultural understanding that nonetheless has become universally transmitted and applied via the structures, sciences and technologies of modernity, with both ecological and social justice implications. An outcome has been the enclosure of landscapes as a core conservation method, alongside the multiple land and resource enclosures that have made possible the structural inequities characterising global industrial society. Attention to this prevailing cognitive landscape helps us to understand why insights about recognition arising from an environmental justice analysis are relatively easy to assert in policy rhetoric, but are resisted in practice (Benjaminsen and Svarstad 2010). We turn now to examining how the absence of recognition, rooted in this dominance of particular ways of knowing, is a serious limitation for currently popular approaches to addressing conservation injustices.

\section{Current justice practices in biodiversity conservation}

This way of knowing biodiversity has informed the progressive allocation of territory to conservation activities, a phenomenon that can be associated with displacements and loss of resource access for local peoples (e.g. Brockington and Igoe 2006; Chapin 2004; Dowie 2009; Brockington and Duffy 2010). Contemporary biodiversity conservation is considerably more sensitive to the desire to mitigate the costs to local people and to an ideal of transforming conservation into a vehicle for development. Thus, as biodiversity conservation has expanded spatially, new management approaches and technologies have been developed, entailing a shift from casting local people as villains (fortress conservation), to stewards (community-based conservation), and now as ecosystem service providers (PES) (Adams and Hutton 2007; Zimmerer 2009). As noted above, a significant policy response to conservation injustice concerns is the recent launch of a Conservation Initiative on Human
Rights by the International Union for the Conservation of Nature, in conjunction with the largest international conservation NGOs (IUCN 2010). Through employing rights-based discourses (e.g. Greiber et al. 2009), this initiative appeals to standards in international law in seeking to promote common and consistent human rights principles in conservation work (Roe et al. 2010).

In practice, however, the most significant interventions to make conservation more fair seek to uphold rights to benefits, via systems of distribution that include revenue-sharing arrangements, compensation schemes, or payment for ecosystem service provision. While we recognise the importance of such instruments for ensuring fair distribution, we nonetheless think it is necessary to confront their problems, as perceived through a justice-as-recognition lens. For example, do the kinds of benefits on offer through current interventions set conditions, such as the need to assimilate into dominant ways of thinking about biodiversity, social relations or development goals? Might benefit-sharing interventions act to subdue difference by enfolding peoples and localities into globally dominant political and economic arrangements, the current form of which is market expansion shaped by neoliberalism (Foucault 2008 [1979]; Sullivan 2006 2011; Fletcher 2010)?

We focus our attention on examples of initiatives intended to balance commercial exploitation of biological resources with the return of economic 'benefits' and/or the protection of indigenous and traditional knowledge. A first example is the 2010 Nagoya Protocol on Access to Genetic Resources and the Fair and Equitable Sharing of Benefits Arising from their Utilization, intended as 'a framework that balances access to genetic resources on the basis of prior informed consent and mutually agreed terms with the fair and equitable sharing of benefits, while taking into account the important role of traditional knowledge' (Secretariat of the CBD 2010, 2). This seeks to limit potential distributional injustice arising from the disproportionate flows of benefits from genetic resources from South to North, flows which historically reflected where the biodiversity and scientific capacity were found (ten Kate and Laird 1999; Rege and Gibson 2003; Smale and Day-Rubenstein 2002). By recognising 'traditional knowledge', ABS agreements attempt to ameliorate the effects of past extraction. However, as Robinson (2010) shows through analysing disputes on benefit flows around Thai rice genetic resources, policy around ABS tends to impose a single understanding of 'biodiversity', 'property' or 'traditional knowledge'. Recognition injustice certainly arises from the consequent obscuring of specific local cultural and historical understandings, but also the resulting tensions can lead to dissent and oppositional biopolitics, posing practical challenges for conservation in the longer term (Brush 2007). Without better recognition of local differences, ABS agreements will 
continue to face charges that they mainly serve to create the conditions for sustaining commercial access to biodiversity resources and knowledge in indigenous territories (e.g. Svarstad 1995; Moeller 2010; de Jonge 2011).

A second example is the widespread use of tourism revenue sharing schemes, especially around protected areas with significant wildlife tourism industry. While these schemes are ostensibly about addressing community concerns about distribution of costs and benefits, Schroeder (2008) documents how in Tanzania they have in practice been more motivated by the desire to gain greater leverage over local communities and further entrench the view that commodifying nature for tourism is the best way to save it and to satisfy local needs. A similar conclusion might be drawn across the border in Rwanda and Uganda, where the lucrative gorilla tourism industry has been a key rationale for strict separation of park and people, sweetened by revenue sharing schemes which, despite sincere intentions to the contrary, yield greatest benefits to the wealthier local residents (Bush et al. 2010). While gorilla tourism has in many ways been very successful, the danger we highlight in this example is that the discursive power of 'selling nature to save it' (McAfee 1999) may preclude alternatives and thereby oppose cultural diversity.

PES, including REDD+, represent another rapidly spreading form of benefit sharing, in which those constituencies who most value (benefit from) conservation of forests and other biodiversity and/or carbon-rich landscapes make economic payments to local people, but conditional on their behaving in certain ways and participating in this dominant way of conceptualising environmental sustainability. PES and REDD+ seek to maintain healthy environments, including biodiversity, by converting these domains into economic prices and creating markets in these, such that 'service users' can 'offset' their own environmental damage (e.g. Perrot-Maître 2006; UNEP/IUCN 2007; Davis 2010) or compensate for the opportunity costs borne by 'service maintainers'. As with the preceding discussion of tourism revenue sharing, it is pertinent to ask what the motives are for such rapid expansion. Fisher (2011) found mixed motives among international conservation NGOs but the most common rationale for embracing ecosystem service and PES approaches was not that it provided a means of fair (re)distribution but that it enabled the NGO itself to access new sources of funding to expand its activities. To an extent, then, even global NGOs feel that there is a dominant way of thinking that they have to assimilate to, and we might suggest that such global-level assimilation gets projected down towards local communities who become hosts to the newly funded conservation interventions. As Spash (2010) observes, the rationale behind carbon trading itself is strongly driven by corporate power and environmental-economic theory that portrays market-based approaches as more efficient than alternatives such as state regulation. However, as we note for tourism revenue sharing, there is a massive gap between theory and reality, with huge obstacles to making carbon payment systems and other PES schemes work for the poor in the real world. For example CARE Uganda pulled out of carbon forestry projects because it proved impossible to reconcile the scheme with their pro-poor mandate (Fisher 2011). It is no longer surprising that benefit sharing and payments schemes are widely contested on grounds of distribution. PES schemes, for example, are critiqued for their inability to accommodate diverse, collective and informal forms of ownership and their favouring of stakeholders who are fortunate enough to own suitable land tracts (Corbera et al. 2007; Schroeder 2008; Böhm and Dabhi 2009; Corbera and Brown 2010). In addition to the practical difficulties of being pro-poor, there are also difficulties of recognising and respecting local people's right to participate as equals. The notion of 'prior and informed consent' is employed with little consideration for challenges of securing this adequately within community constituencies. There is a large literature on the limitations of professionalised procedures for participation and deliberation (Chilvers 2009) and it has to be asked how local knowledge and views can really be protected, and what are the real safeguards, if any, against the top-down imposition of ways of knowing.

Viewed through the lens of distributional justice, and given a global context that locates both high poverty and high biodiversity in the global South, ABS and PES might be argued to be mechanisms for improved distribution. In economic theory, they are efficient, they create new property rights over newly commodified environmental goods, they allocate decisionmaking powers (to consent to enter the market or not), and they assure either a share in benefits from exploitation, or compensation for foregone exploitation. Thus they can redistribute benefits and/or costs in ways potentially favourable to the poor. While the emphasis on the nation-state (e.g. in CBD and REDD) is problematic because the interests of states too rarely align with marginalised groups, even this can be presented as progressive in the context of vast wealth disparities between North and South (Schroeder and Pogge 2009). PES might then have potential for poverty alleviation (Pagiola et al. 2005; Wunder 2008) and this is a key reason behind narratives of multiple win scenarios, with the theoretical potential to align interests in biodiversity conservation, climate change mitigation, poverty reduction and local empowerment (while reassuring those stakeholders who are committed to continued growth in carbon-based economies). What we hope to have done here, albeit briefly, is to assert that the real world rarely looks like this, and that these schemes are often 
frail when scrutinised for distributional justice. Moreover, for the current argument, they potentially perpetuate failures of recognition through the extension of popular, dominant conceptions of environmental sustainability.

\section{Social justice and environmental sustainability}

As constituted in prevalent ways of thinking about society and nature, there often appear to be conflicts between the demands of biodiversity conservation for the many and demands for social justice by the few who live near to its 'hotspots'. The separation of environmental and social in moral thinking is in part a product of the perceived contest between the fear of extinction, with its repercussions for the common heritage, and the desire to respect human rights, for example with respect to displacement (a tension between consequentialist and deontological thinking). Working along this fault line, Dobson (2007) sees little prospect for reconciling social and environmental justice because there is no evidence that social justice is either a precondition for, or a product of, biological conservation. He arrives at the reluctant conclusion that social justice and environmental sustainability are not always compatible objectives' even though we might dearly wish them to be so, because 'sustainability is about preservation and/or conservation; justice is about distribution' $(2007,83,93)$. Dobson's careful analysis of this difference finds only one case of common ground, in the area of intergenerational justice. While species loss might not produce injustices within the current generation, he argues that it does clearly produce injustice towards future generations and in this particular respect the objectives of social justice and environmental sustainability are demonstrably aligned.

The question of whether we can align the objectives of social and environmental justice appears critical if we are to achieve approaches to biodiversity conservation that are less conflictive than they have sometimes been. We wonder whether this apparent tension between social and environmental justice becomes more resolvable through a conceptualisation of justice that extends beyond distribution to include recognition? For biodiversity conservation, we have seen that the problem of recognition revolves around the dominance of ways of knowing that dichotomise people and nature, and which seek to resolve overexploitation of nature through a form of reconnection based on commoditisation. The problem of malrecognition is therefore connected to the problem of reconciling social justice with sustainability, as both problems are linked to a way of knowing that involves the separation of nature and society.

The concept of biocultural diversity might prove useful in addressing these dual separations, and so help reconcile social and environmental concerns about biodiversity. Research into biocultural diversity points out the co-occurrence of biological and linguistic diversity 'hotspots' (Gorenflo et al. 2012), and argues that this is not coincidental but rather that cultural diversity and biological diversity are to some degree mutually supportive (Maffi 2001; Maffi and Woodley 2010). The role of culture in shaping biodiversity is increasingly appreciated, particularly for 'domesticated' biodiversity, where growing evidence shows how crop genetic diversity is (re)created by culturally specific management practices and norms, interacting with the biophysical environment (Leclerc and d'Eeckenbrugge 2012; McGuire 2008; Caillon and Degeorges 2007). Consequently, recognition of specific ways of knowing poses no major problems for in situ conservation of domesticated crop diversity, particularly as cultural diversity - and cultural change - are essential for maintaining dynamic, and adapted, biodiversity assemblages (Louette et al. 1997). For less 'domesticated' biological diversity, there is also evidence that indigenous economies and management practices can support conservation (Gorenflo et al. 2012). However, few conservation programmes for 'wild' biodiversity promote different ways of knowing - so the impact of cultural recognition on conservation outcomes remains an open question. Empirical and programmatic debates will continue around biocultural diversity, but the concept's value is to show that the separation of nature and society is artificial, and for conservation possibly counter-productive.

This is not to privilege any particular type of cultural diversity, or to romanticise indigenous cultures as essentially ecological. Rather it is to assert that a diversity-friendly justice (which will be acceptable to many on the left) can also be a biodiversity-friendly justice. As such we suggest that a broader engagement with the underpinnings of environmental distributions, combined with awareness of the complexities and subtleties in biocultural assemblages and knowledges alluded to above, offers more fertile ground for a shared justice discourse. Having ventured down this line of thinking, we also wonder to what extent the concept 'environmental justice' is (or should be) a category distinct from 'social justice'? It seems to us that separating these domains can become a problematic mirror of the onto-epistemological distinction between 'culture' and 'nature' that arguably has produced the global 'socio-environmental justice' concerns we currently face (cf. Viveiros de Castro 2004; Plumwood 2006; Curry 2008).

\section{Conclusion}

Biodiversity clearly is an arena infused and populated with vibrant justice issues, at multiple and connecting scales of observation and experience. In closing this paper, without dismissing the justice achievements of modern distributive and rights-based discourses and legislation, we note that participation in this universalising language can itself become a means by which 
diversity of knowledge practices become occluded and displaced. As such, we call for the maintenance of robust political economy analyses of the locations and alliances of contemporary 'socio-environmental justice' issues with nuanced understanding of the roles of capitalist structures and assumptions in the production and mitigation of these issues. In this, we ask to what extent a global environmental justice may enhance the field of political ecology in understanding the emergence of specific global socioenvironmental justice issues, and in providing critical understandings of the roles of power in delineating, causing and distributing environmental 'goods and bads' (cf. Atkinson 1991; Forsyth 2003).

Global policy innovations that attempt to align the management of biodiversity for conservation, economic growth and social justice tend to do this in ways that are uncritical of, and in fact sustain, a neoliberal political economic framework that shores up market-based mechanisms and makes these different arenas compatible by constituting all of their referents in economic terms and measures. The intention is to manage capitalism/economic growth for environmental conservation and social justice, at the same time as turning these latter domains themselves into possibilities for capital value accumulation. But this way of framing society-nature relations denies prospects for spatial difference, for selfdetermination, for subsistence autonomy, and for nurturing non-modern socio-ecological values and practices. As approaches to making possible radical forms of equity and justice in distributive, procedural or cognitive/onto-epistemological terms, these are severely constrained. It is with this understanding that engagement with the new referent of 'global environmental justice' might attain meaning and traction.

\section{Acknowledgements}

We would like to acknowledge the very helpful suggestions from two anonymous reviewers.

\section{References}

Adams W A 2004 Against extinction: the story of conservation Routledge, London

Adams W and Hutton J 2007 People, parks and poverty: political ecology and biodiversity conservation Conservation and Society 5 147-83

Atkinson A 1991 Principles of political ecology Belhaven Press, London

Belenky M F, Clinchy B V, Goldberger N R and Tarule J M 1986 Women's ways of knowing: the development of Self, voice and mind Basic Books, New York

Benjaminsen T and Svarstad H 2010 The death of an elephant: conservation discourses versus practices in Africa Forum for Development Studies 37 385-408
BirdLife International 2011 An introduction to conservation and human rights for BirdLife Partners BirdLife International, Cambridge

Böhm S and Dabhi S eds 2009 Upsetting the offset: the political economy of carbon markets MayFly Books, London

Bohman J 2007 Beyond distributive justice and struggles for recognition: freedom democracy and critical theory European Journal of Political Theory 6 267-76

Briggs B D J, Hill D A and Gillespie R 2009 Habitat banking how it could work in the UK Journal for Nature Conservation 17 112-22

Brockington D and Duffy R 2010 Conservation and capitalism: the production and reproduction of biodiversity conservation Antipode 42 469-84

Brockington D and Igoe J 2006 Eviction for conservation: a global overview Conservation and Society 4 424-70

Brockington D, Igoe J and Duffy R 2008 Nature unbound: conservation, capitalism and the future of protected areas Earthscan, London

Brooks T M, Mittermeier R A, Mittermeier C G, Da Fonseca G A B, Rylands A B, Konstant W R, Flick P, Pilgrim J, Oldfield S, Magin G and Hilton-Taylor C 2002 Habitat loss and extinction in the hotspots of biodiversity Conservation Biology 16 909-23

Brush S B 2007 Farmers' rights and the protection of traditional agricultural knowledge World Development 35 1499-514

Bullard R D 1990 Dumping in Dixie: race, class and environmental quality Westview Press, Boulder, CO

Bush G, Ikirezi M, Daconto G, Gray M and Fawcett K 2010 Assessing impacts from community conservation interventions around Parc National des Volcans Dian Fossey Gorilla Fund International, Rwanda

Caillon S and Degeorges P 2007 Biodiversity: negotiating the border between nature and culture Biodiversity Conservation 16 2919-31

Carroll N, Fox J and Bayon R 2008 Conservation and biodiversity banking: a guide to setting up and running biodiversity credit trading systems Earthscan, London

Castree N 2004 Differential geographies: place indigenous rights and 'local' resources Political Geography 23 133-67

Chan K and Satterfield T 2007 Justice, equity and biodiversity in Levin S, Daily G C and Colwell R K eds The encyclopedia of biodiversity Elsevier, Oxford 1-9

Chapin M 2004 A challenge to conservationists World Watch Magazine November/December 16-31

Chilvers J 2009 Deliberative and participatory methods in environmental geography in Castree N, Demeritt D, Liverman D and Rhoads B eds A companion to environmental geography Wiley-Blackwell, Chichester 400-17

Corbera E and Brown K 2010 Offsetting benefits? Analyzing access to forest carbon Environment and Planning A 42 1739-61

Corbera E, Brown K and Adger W N 2007 The equity and legitimacy of markets for ecosystem services Development and Change 38 587-613

Curry P 2008 Nature post-nature New Formations 26 5164

Davis A I 2010 Ecosystem services and the value of land Duke Environmental Law and Policy Forum 20 339-84 
de Jonge B 2011 What is fair and equitable benefit-sharing? Journal of Agricultural and Environmental Ethics 24 12746

De Landa M 2006 A New Philosophy of society: assemblage theory and social complexity Continuum, London

Deleuze G and Guattari F 1987 [1980] A thousand plateaus: capitalism and schizophrenia Massumi B trans The Athlone Press, London

Dobson A 2007 Social justice and environmental sustainability: ne'er the twain shall meet? in Agyeman J, Bullard R and Evans B eds Just sustainabilities: development in an unequal world MIT Press, Cambridge, MA 83-95

Dowie M 2009 Conservation refugees: the hundred-year conflict between global conservation and native peoples MIT Press, Cambridge MA

Escobar A 1998 Whose knowledge, whose nature? Biodiversity conservation and the political ecology of social movements Journal of Political Ecology 5 53-82

Fisher J 2011 Payment for ecosystem services in forests: analysing innovations policy debates and practical implementation Unpublished PhD thesis, University of East Anglia

Fletcher R 2010 Neoliberal environmentality: towards a poststructural political ecology of the conservation debate Conservation and Society 8 171-81

Forsyth T 2003 Critical political ecology: the politics of environmental science Routledge, London

Foucault M 2008 [1979] The birth of biopolitics: lectures at the Collège de France 1978-1979 Burchell G trans Palgrave Macmillan, Basingstoke

Fraser N 1997 Justice interruptus Routledge, London

Fraser N 2001 Recognition without ethics? Theory, Culture and Society 18 21-42

Fraser N 2009 Scales of justice: reimagining political space in a globalizing world Columbia University Press, New York

Gaston K J 2000 Global patterns in biodiversity Nature 405 $220-7$

Global Forest Coalition 2010 Biodiversity summit adopts binding decisions against biopiracy and geo-engineering Press release (www.globalforestcoalition.org) Accessed 26 January 2013

Gorenflo L J, Romaine S, Mittermeier R A and Walker-Painemilla K 2012 Co-occurrence of linguistic and biological diversity in biodiversity hotspots and high biodiversity wilderness areas Proceedings of the National Academy of Science in press. doi:10.1073/pnas.1117511109

Greiber T, Janki M, Orellana M, Savaresi A and Shelton D 2009 Conservation with justice: a rights-based approach IUCN Environmental Policy and Law Paper No. 71 IUCN, Gland

Harvey D 1996 Justice, nature and the geography of difference Blackwell, Oxford

IUCN 2010 Conservation initiative on human rights (www.iucn.org/about/work/programmes/social_policy/sp_ themes_hrande/scpl_cihr/) Accessed 10 August 2010

Jamieson D 1994 Global environmental justice Royal Institute of Philosophy Supplement 36 199-210

Latour B 2004 Politics of nature: how to bring the sciences into democracy Harvard University Press, Cambridge MA
Latour B 2005 Reassembling the social: an introduction to actornetwork theory Oxford University Press, Oxford

Leclerc C and d'Eeckenbrugge G C 2012 Social organization of crop genetic diversity. The $\mathrm{G} \times \mathrm{E} \times \mathrm{S}$ interaction model Diversity 4 1-32

Louette D, Charrier A and Berthaud J 1997 In situ conservation of maize in Mexico: genetic diversity and maize seed management in a traditional community Economic Botany 51 20-38

Maffi L 2001 Language, knowledge, and indigenous heritage rights in Maffi L ed On biocultural diversity: linking language, knowledge, and the environment Smithsonian Institution Press, Washington DC 412-32

Maffi L and Woodley E eds 2010 Biocultural diversity conservation: a global sourcebook Earthscan, London

Marx K 1974 [1887] Capital: a critical analysis of capitalist production Engels F ed Moore S and Aveling E trans Lawrence and Wishart, London

McAfee K 1999 Selling nature to save it? Biodiversity and the rise of green developmentalism Environment and Planning D: Society and Space 17 133-54

McGuire S J 2008 Securing access to seed: social relations and sorghum seed exchange in eastern Ethiopia Human Ecology 36 217-29

McNay L 2008 Against recognition Polity Press, Cambridge

Moeller N 2010 The protection of traditional knowledge in the Ecuadorian Amazon: a critical ethnography of capital expansion Unpublished PhD thesis, University of Lancaster

Nicolson A 2009 Arcadia: England and the Dream of Perfection Harper Perennial, London

Norgaard R 2010 Ecosystem services: from eye-opening metaphor to complexity blinder Ecological Economics 69 1219-27

Pagiola S, Arcenas A and Platais G 2005 Can payments for environmental services help reduce poverty? World Development 33 237-53

Perrot-Maître D 2006 The Vittel payments for ecosystem services: a 'perfect' PES case? International Institute for Environment and Development (IIED), London

Pistorius R 1997 Scientists, plants, and politics: a history of the plant genetic resources movement International Plant Genetic Resources Institute, Rome

Plumwood V 2006 The concept of a cultural landscape: nature culture and agency in the land Ethics and the Environment 11 115-50

Rawls J 1999 [1971] A theory of justice Harvard University Press, Cambridge MA

Rege J E O and Gibson J P 2003 Animal genetic resources and economic development: issues in relation to economic valuation Ecological Economics 45 319-30

Robinson D F 2010 Locating biopiracy: geographically and culturally situated knowledges Environment and Planning A 42 38-56

Roe D, Oviedo G, Pabon L, Painter M, Redford K, Siegele L, Springer J and Walker-Painemilla K 2010 Conservation and human rights: the need for international standards IIED Briefing May

Schipper J, Chanson J S, Chiozza F, Cox N A, Hoffmann M, Katariya V, . . \& Hammond P S 2008 The status of the world's land and marine mammals: diversity, threat and knowledge Science 322 225-30 
Schlosberg D 2004 Reconceiving environmental justice: global movements and political theories Environmental Politics 13 517-40

Schlosberg D 2007 Defining environmental justice: theories, movements and nature Oxford University Press, Oxford

Schroeder R 2008 Environmental justice and the market: the politics of sharing wildlife revenues in Tanzania Society and Natural Resources 21 583-96

Schroeder D and Pogge T 2009 Justice and the convention on biological diversity Ethics \& International Affairs 23 26780

Secretariat of the CBD 2010 A new era of living in harmony with Nature is born at the Nagoya Biodiversity Summit Press release, 10th Conference of Parties (www.cbdint/doc/press/ 2010/pr-2010-10-29-cop-10-enpdf) Accessed 7 January 2011

Smale M and Day-Rubenstein K 2002 The demand for crop genetic resources: international use of the US national plant germplasm system World Development 30 1639-55

Spash C L 2010 The brave new world of carbon trading New Political Economy 15 169-95

Sullivan S 2006 The elephant in the room? Problematizing 'new' (neoliberal) biodiversity conservation Forum for Development Studies 33 105-35

Sullivan S 2011 Conservation is sexy! What makes this so, and what does this make? An engagement with celebrity and the environment Conservation and Society 9 102-13

Svarstad H 1995 Biodiversity prospecting: biopiracy or equitable sharing of benefits? Oslo Centre for Development and the Environment, University of Oslo

ten Kate K and Laird S A 1999 The commercial use of biodiversity: access to genetic resources and benefit-sharing Earthscan, London

Terborgh J W 1999 Requiem for nature Island Press, Washington DC

Thompson E P 1977 Whigs and hunters: the origin of the Black Act Penguin Books, London

UNEP 2011 Working towards sustainable development: opportunities for decent work and a green economy (http:// www.ilo.org/wcmsp5/groups/public/—ed_emp/—emp_ent/ documents/publication/wcms_181836.pdf) Accessed 7 June 2012

UNEP/IUCN 2007 Developing international payments for ecosystem services: towards a greener world economy (www.unepch/etb/areas/pdf/IPES_IUCNbrochure.pdf)

Accessed 23 September 2010

Vermeylen S and Walker G 2011 Environmental justice, values and biological diversity: the San and the Hoodia benefit sharing agreement in Carmin J and Agyeman J eds Environmental inequalities beyond borders: local perspectives on global injustices MIT Press, Cambridge, MA 105 28

Vincent A 1998 Is environmental justice a misnomer? In Boucher D and Kelly P eds Social justice: from Hume to Walzer Routledge, London 120-40

Viveiros de Castro E 2004 Exchanging perspectives: the transformation of objects into subjects in Amerindian ontologies Common Knowledge 10 463-84

Walker G 2012 Environmental justice: concepts, evidence and politics Routledge, London

WCS 2009 Conservation and human rights: a framework for action 18 October (http://cmsdata.iucn.org/downloads/hr_ framework_wcs_1.pdf) Accessed 1 February 2013

Whiteman G 2009 All my relations: understanding perceptions of justice and conflict between companies and indigenous peoples Organization Studies 30 101-20

Wilson EO ed 1988 Biodiversity National Academy Press, Washington DC

Wittemyer G, Elsen P, Bean W T, Burton A C O and Brashares J S 2008 Accelerated human population growth at protected area edges Science 321 123-6

Workshop Report 2012 Rights-based approaches to REDD+: report of a conservation initiative on Human Rights Workshop, Lima, Peru 24-26 January 2012 (https://community.iucn.org/ cihr/Resources/CIHR-REDD+WorkshopReport.pdf) Accessed 7 June 2012

World Bank Group 2012 Toward a green, clean, and resilient World for all: a World Bank Group environment strategy 20122022 (http://siteresources.worldbank.org/ENVIRONMENT/ Resources/ENV_Strategy_Summary.pdf\#Page=10) Accessed 6 June 2012

Wunder S 2008 Payments for environmental services and the poor: concepts and preliminary evidence Environment and Development Economics 13 279-97

WWF 2008 Indigenous peoples and conservation: WWF statement of principles WWF International, Gland

WWF 2010 Living Planet Report 2010 (http://awsassets. panda.org/downloads/wwf_lpr2010_Ir_en.pdf) Accessed 1 February 2013

Zalasiewicz J, Williams M, Steffen W and Crutzen P 2010 The new world of the Anthropocene Environmental Science \& Technology 44 2228-31

Zimmerer K 2009 Biodiversity in Castree N, Demeritt D, Liverman D and Rhoads B eds A companion to environmental geography Wiley-Blackwell, Chichester 50-65 